\title{
Evaluation and Optimization of Downstream Process Parameters for Extraction of Betulinic Acid from the Bark of Ziziphus jujubae L.
}

\author{
Kashyap Kumar Dubey and Nitika Goel \\ Microbial Biotechnology Laboratory, University Institute of Engineering and Technology, MD University, Rohtak, \\ Haryana 124001, India \\ Correspondence should be addressed to Kashyap Kumar Dubey; kashyapdubey@yahoo.com
}

Received 17 August 2013; Accepted 11 September 2013

Academic Editors: A. P. Borole and M. C. Yebra-Biurrun

Copyright (c) 2013 K. K. Dubey and N. Goel. This is an open access article distributed under the Creative Commons Attribution License, which permits unrestricted use, distribution, and reproduction in any medium, provided the original work is properly cited.

Present work investigated an apposite and efficient method for extraction of betulinic acid (BA) from the bark of Ziziphus jujubae. Various extraction methods like stirring extraction, soxhlet extraction, ultrasonic extraction, and microwave assisted extraction (MAE) were evaluated for increasing recovery percentage of BA. From the raffinate so obtained, BA was isolated. Thin layer chromatography (TLC) was used to analyze the extract and high performance liquid chromatography (HPLC) for quantification. The results revealed that the percentage extraction of BA from Z. jujubae by MAE was more proficient. As recovery percentage of BA by MAE technique turned out to be maximum, by using response surface methodology (RSM), three process parameters ( $\mathrm{pH}$, temperature, and time) were optimized by MAE and it was observed that the optimum parameters $\left(\mathrm{pH} 6.5\right.$, temp. $70.23^{\circ} \mathrm{C}$, and time $3.5 \mathrm{~min})$ gave the maximum recovery of BA $(0.44 \% \mathrm{w} / \mathrm{w})$. To validate the RSM model, experiments were performed and the highest recovery of BA was found to be $0.4 \% \mathrm{w} / \mathrm{w}$ which is $\pm 0.04 \%$ to the predicted value. Henceforth the extraction efficiency and the substantial saving of time by MAE was more capable than the other extraction techniques.

\section{Introduction}

Betulinic acid ( $3 \beta$-hydroxy-lup-20-en-28-oic acid) is a naturally occurring pentacyclic lupane-type triterpenoid unveiling a variety of biological and medicinal properties such as inhibition of human immunodeficiency virus (HIV), antibacterial, antimalarial, anti-inflammatory [1], antihelmintic, antinociceptive, anti-HSV-1, and anticancer activities. Betulinic acid acts through inhibition of the enzymes in the arachidonic [2] acid pathway turning out to be a powerful antiphlogistic [3] agent. BA, as shown in Figure 1, induces apoptosis, that is, the controlled death of a cancer cell, butdoes not affect normal cells [4].

Distribution of $\mathrm{BA}$ is very wide in the plant kingdom with birch tree (Betula spp., Betulaceae) as one of the most extensively stated sources. Also from the various other sources including Ziziphus spp. (Rhamnaceae) [5], Syzygium spp.
(Myrtaceae), Diospyros spp. (Ebenaceae), and Paeonia spp. (Paeoniaceae), BA can be isolated.

The jujube fruit originated in China and it is known to stimulate the body, increase metabolism, give strength to the heart, and slow down the aging process. It is rich in calcium, protein, and Vitamins C, B1, B2, and A. Jujube encourages cell turnover, improves elasticity and firmness of skin, and reduces the appearance of scars and stretch marks. There are very few plants or trees which are admired by the Chinese as the jujube tree due to its medications [6] resulting from treatment with extracts from the Chinese jujube. Experiments show that Ziziphus jujubae possesses immense pharmacological properties like antiaging effects, anti-inflammatory effects, anticancer and antiviral effects, and antiparasitic effects.

Previous reports have shown that the extraction and product recovery are the most imperious steps in the evaluation of the target molecules from various plant parts. 


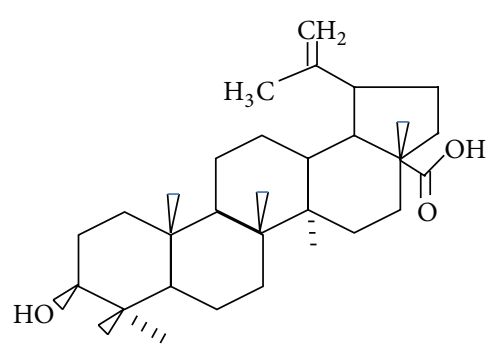

FIgURE 1: Chemical structure of betulinic acid.

Generally the extraction processes consume a lot of time and bulk amount of solvents. Stirring extraction methods [7] are used for the extraction of biological active compounds [8]. Soxhlet extraction technique [9] is applied for various compounds taking more than $24 \mathrm{~h}$ for extraction leading to wastage of large amount of solvents. In ultrasonic extraction (USO), high frequency sound [10] is used to interrupt the target compound from the plant materials. USO has been used for the extraction of saponin from ginseng [11] and also other phytochemicals [12] from different parts of plants. Microwave assisted extraction (MAE) system for extraction of biologically active compounds has many advantages over other conventional extraction methods [13] as it requires shorter time, less solvents, higher extraction rate, and better products with lower costs. Plentiful compounds have been extracted using MAE, such as extraction of glycyrrhizic acid from Glycyrrhiza glabra root and extraction of artemisinin from Artemisia annua [8].

Normally, in the downstream processes, the optimum conditions are determined by keeping one variable parameter and others at constant level, which is a very time consuming process. Box and Wilson [14] devised response surface methodology (RSM), a statistical approach, which turns out to be an effective tool for optimization process to reduce the time involved in performing so many experiments.

The present research aimed to develop a suitable efficient downstream process for the maximum recovery of BA using central composite design (CCD) of RSM to evaluate and understand the process parameters individually as well as their interactions. On the basis of previous reports $[7-9,11]$, the authors have chosen few extraction procedures, namely, stirring extraction, soxhlet extraction, ultrasonic extraction, and MAE for enhancement in recovery of BA from the bark of Ziziphus jujubae.

\section{Materials and Methods}

2.1. Plant Material and Reagents. Plant material of Z. jujubae was provided by Sai Phytoceuticals, New Delhi, India. The bark was dried at $55^{\circ} \mathrm{C}$ in air dryer for $45 \mathrm{~h}$. Dried material was pulverized by miller. Ethanol, methanol, hexane, acetone, and ethyl acetate were of analytical grade chemicals (SISCO Research Lab, Mumbai, India). Petroleum ether, dichloroethylene, and acetic acid were used for TLC (Merck, Mumbai, India). Acetonitrile and water were used for HPLC of reagent of HPLC grade (SRL, Mumbai, India).

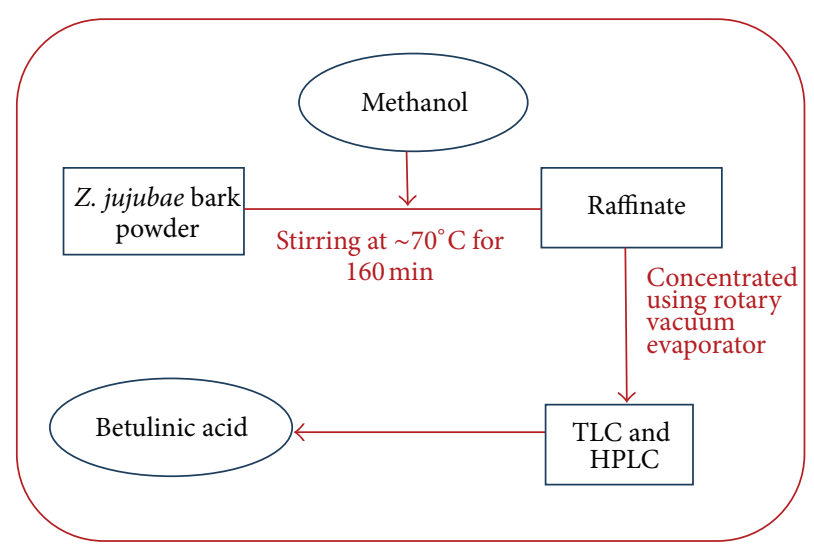

FIGURE 2: Line diagram for stirring extraction method.

2.2. Extraction Procedures and Related Parameters. Four types of extraction procedures, namely, stirring extraction, ultrasonic extraction, soxhlet extraction, and microwave assisted extraction, were tried. Parameters that were optimized were choice of solvent, material: solvent ratio, $\mathrm{pH}$, process time, and temperature for the maximum recovery of BA from the bark of $Z$. jujubae. The procedures for the optimization of the above described parameters using different extraction techniques are as follows.

Stirring extraction was carried out on a magnetic stirrer furnished with a hot plate. Ground bark material of Z. jujubae was extracted with ethanol, methanol, hexane, acetone, and ethyl acetate in similar concentrations at $70^{\circ} \mathrm{C}$ for $160 \mathrm{~min}$ (Figure 2) successively at a speed of $160 \times \mathrm{g}$. After extraction, the raffinates were filtered through filter paper and vacuum dried using rotary vacuum evaporator. The filtrates were isolated by TLC and subsequently analyzed by HPLC. The stirring extraction procedure was repeated with methanol at different $\mathrm{pH}$ and varying bark material : methanol ratios.

Ultrasound assisted extraction was accomplished in an ultrasonic bath with a working frequency of $35 \mathrm{KHz}$. Twogram Z. jujubae plant material (Figure 3) was extracted with methanol (100 mL) and kept for sonication for 20, 30, 40, 50, and $60 \mathrm{~min}$ at room temperature sequentially.

During soxhlet extraction (Figure 4), in the $200 \mathrm{~mL}$ soxhlet thimble, $2 \mathrm{~g}$ of dried bark powder was set and the apparatus was fixed with a round bottom flask holding $100 \mathrm{~mL}$ of methanol. The extraction was carried out at $68^{\circ} \mathrm{C}$ for 40,60 , $80,100,120$, and $140 \mathrm{~min}$, and after a given time, the solvent was refluxed.

For microwave assisted extraction, Z. jujubae dried bark powder $(2 \mathrm{~g}$ ) was put into a $100 \mathrm{~mL}$ flask to which $100 \mathrm{~mL}$ of methanol was added. The flask was then exposed for $4 \mathrm{~min}$ in a microwave oven at $100 \mathrm{~W}$. Superboiling was not allowed as the microwave irradiation was stopped for a minute and was cooled underneath running water for $2 \mathrm{~min}$, and then the same flask was exposed to microwave irradiation (Figure 5) after cooling.

2.3. Optimization of Process Parameters in MAE Using RSM. The three most significant factors $(A: \mathrm{pH}, B$ : time, and $C$ : temperature) in MAE technique, affecting the extraction 


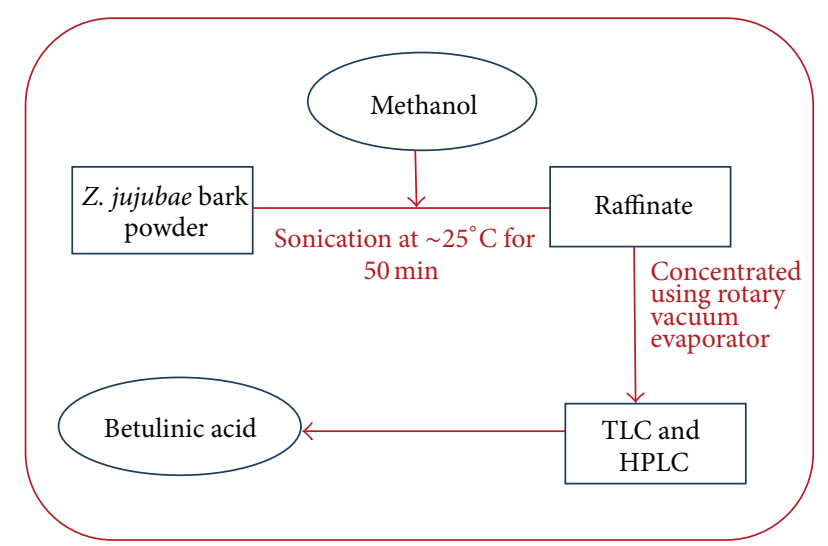

FIGURE 3: Line diagram for ultrasonic assisted extraction method.

TABLE 1: Ranges of various independent process variables (temperature, $\mathrm{pH}$, and process time) used in RSM.

\begin{tabular}{lccc}
\hline \multirow{2}{*}{ Factor } & \multirow{2}{*}{ Name } & \multicolumn{2}{c}{ Range studied } \\
& & Low level & High level \\
\hline$A$ & $\mathrm{pH}$ & 3.00 & 10.00 \\
$B$ & Time & 2.00 & 5.00 \\
$C$ & Temp. & 30.00 & 60.00 \\
\hline
\end{tabular}

rate of $\mathrm{BA}$, were optimized using $\mathrm{CCD}$. To produce and examine the experimental design, the statistical software "Design Expert 8.0" was employed. A set of 20 different runs were carried out and the maximum recovery $\%$ of BA (w/w) was used as response on accomplishment of the experiments. To obtain an empirical model, linking the response measured with the independent variables, multiple regression of the data was also carried out. Using the "Design Expert" software, 3D graphs were formed to define the optimum levels of the variables for maximum yield of BA. Table 1 shows the experimental range for each variable using the classical optimization approach where one parameter was changed while others were kept constant.

2.4. Chromatography Analysis. The raffinates obtained from different extraction methods were filtered and concentrated by rotary vacuum evaporator and then BA was isolated using TLC. TLC was performed in silica gel as a stationary phase and the solvents used as mobile phase were petroleum: dichloroethylene: acetic acid $(50: 50: 0.7)$. The betulinic acid was detected by spraying $20 \%$ antimony chloride in chloroform.

The HPLC analyses were carried out on furnished YL instrument. The betulinic acid was determined by using $84 \%$ acetonitrile and $16 \%$ water as mobile phase. The flow rate was $1 \mathrm{~mL} / \mathrm{min}$ and the elution was monitored at $210 \mathrm{~nm}$. Validation of quantitative method was done with sample three times.

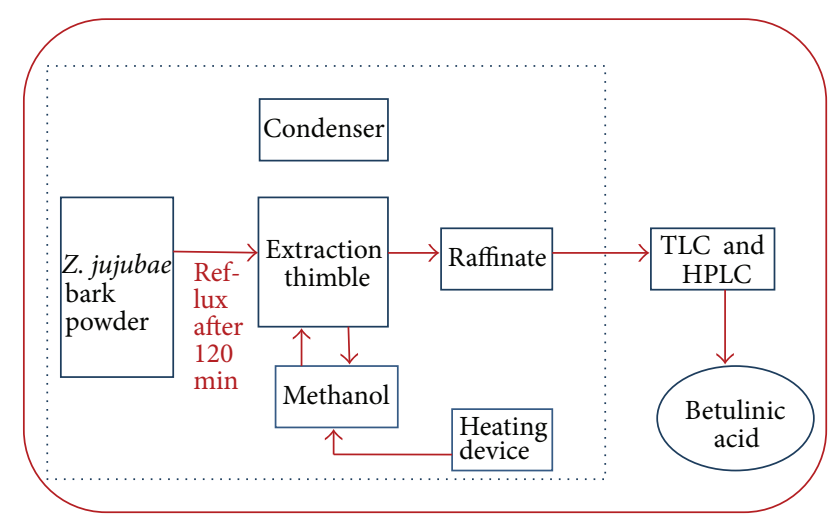

FIGURE 4: Line diagram for soxhlet extraction method.

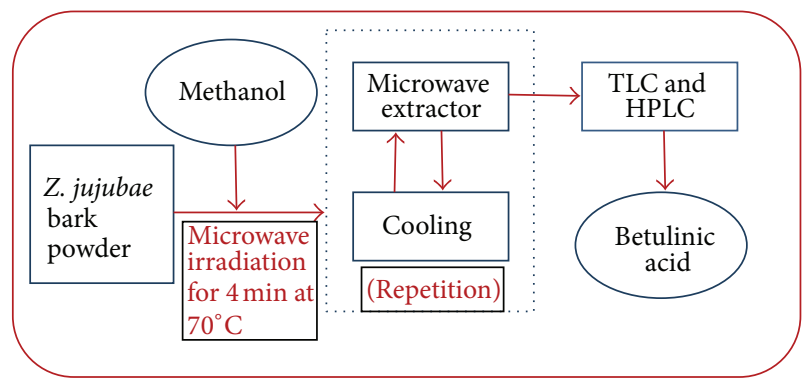

FIGURE 5: Line diagram for microwave assisted extraction (MAE) method.

\section{Results and Discussion}

Betulinic acid is a pentacyclic lupane-type triterpenoid which exhibits various biological and medicinal properties such as antibacterial, antimalarial, antiinflammatory, anthelmintic, antinociceptive, anti-HSV-1, and anticancer activities [1,3]. Previous researchers have been exploiting stirring extraction, ultrasonic extraction, soxhlet extraction, and MAE for extraction of BA. In the present study, the authors have investigated suitable techniques among the above mentioned methods for the recovery of BA from the bark of $Z$. jujubae. Figure 6 depicts the line diagram of downstream process for the recovery of BA from the bark of $Z$. jujubae.

The extraction parameters were optimized and the results are given below.

3.1. Selection of an Appropriate Solvent. Various organic solvents (methanol, ethanol, acetone, ethyl acetate, and hexane) were used in the extraction of BA from the bark of Z. jujubae. The maximum recovery of BA $(0.27 \% \mathrm{w} / \mathrm{w})$ was obtained when methanol was used as organic solvent as compared to the other solvent systems (Figure 7). Previous literature reported that methanol was found to be most reactive with the plant material during extraction of secondary metabolites [15] especially terpenes. Generally, methanol was regarded as a safe solvent system for extraction of medicinally important metabolites. Keeping in view the above facts, methanol was used as a solvent for further extraction procedures. 


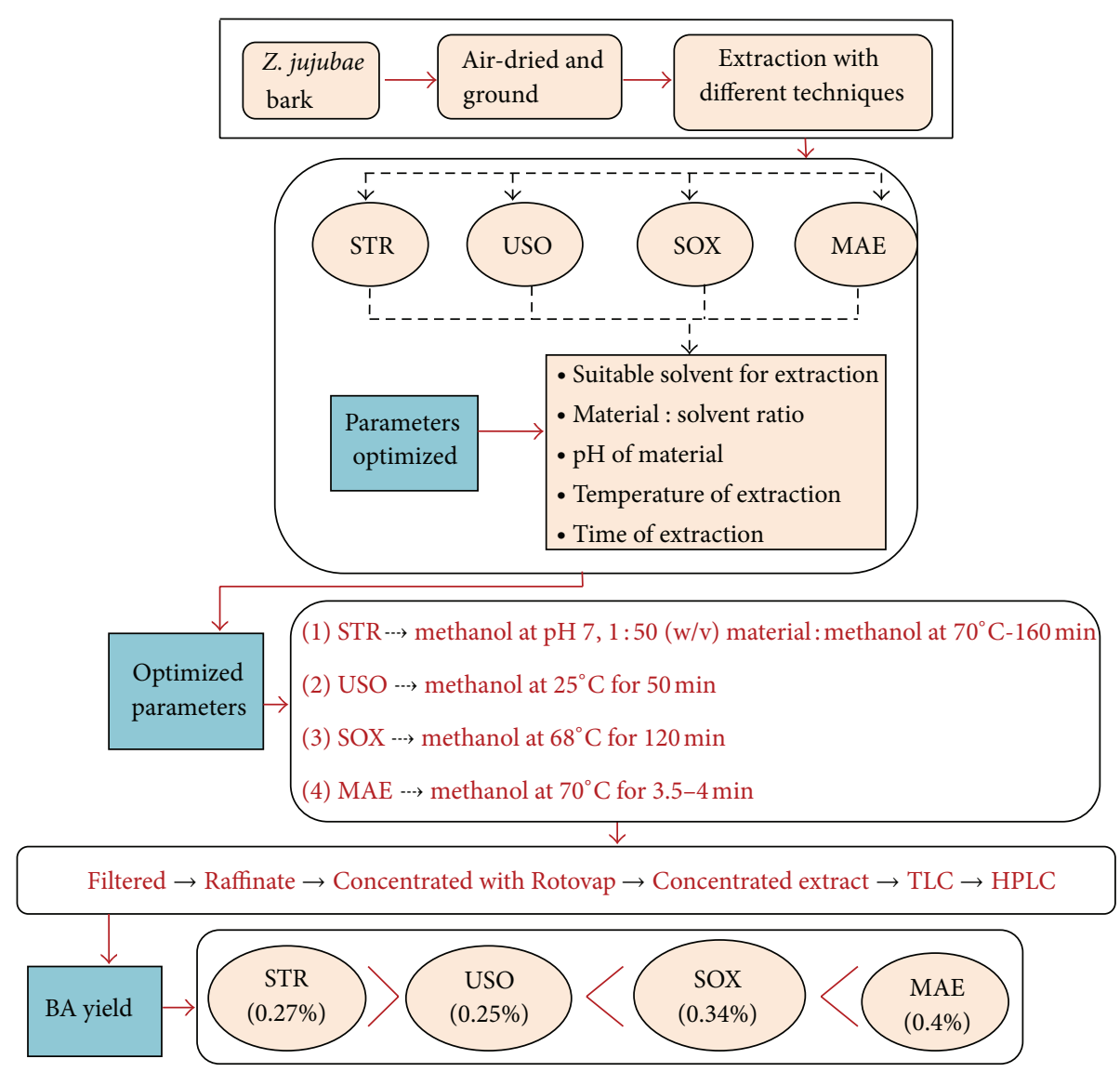

FIGURE 6: Representation of the complete process for recovery of BA from the bark of Z. jujubae (STR: stirring extraction; USO: ultrasonic extraction; SOX: soxhlet extraction; MAE: microwave assisted extraction).

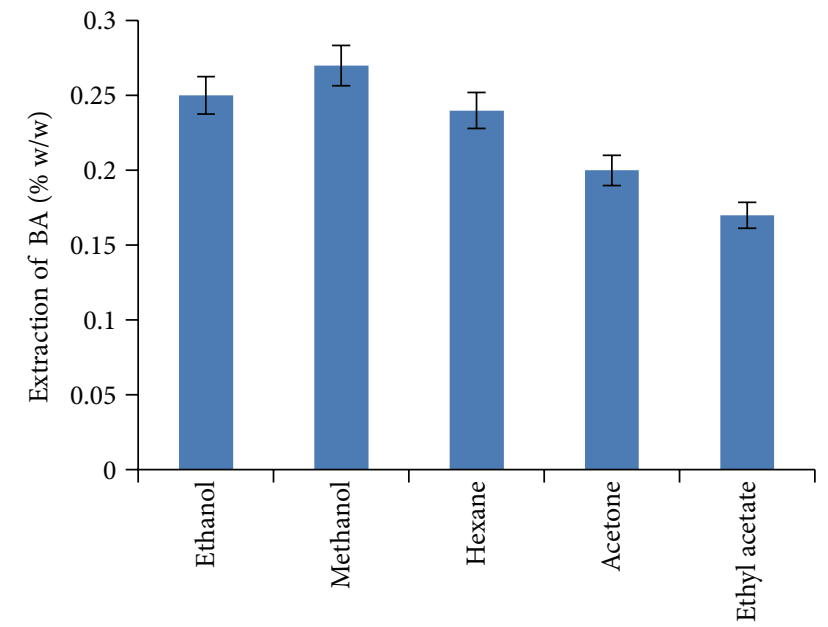

Solvents

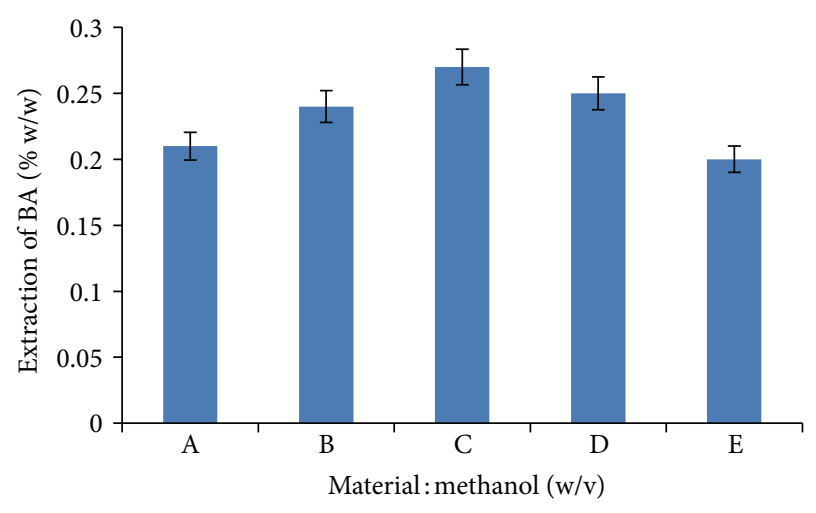

FIGURE 8: The effect of stirring extraction at varying material : solvent ratios $(A=1: 30, B=1: 40, C=1: 50, D=1: 60$, and $E=$ $1: 70)$.

FIGURE 7: The effect of stirring extraction with various solvents at $70^{\circ} \mathrm{C}$ for $160 \mathrm{~min}$.

3.2. Optimization of Material: Solvent Ratio. To minimize the cost of the recovery process several material: solvent ratios were tried. The different material : solvent (methanol) ratios

were $1: 30,1: 40,1: 50,1: 60$, and $1: 70$ at lab-scale level. Figure 8 shows that the 1:50 material: methanol ratio gave the maximum recovery $(0.27 \% \mathrm{w} / \mathrm{w})$ of BA. So, further in the study, 1:50 ratio was used for the extraction of BA. Hence, to reduce the excess solvent usage, 1:50 material: methanol ratio was used in USO, SOX, and MAE techniques. 


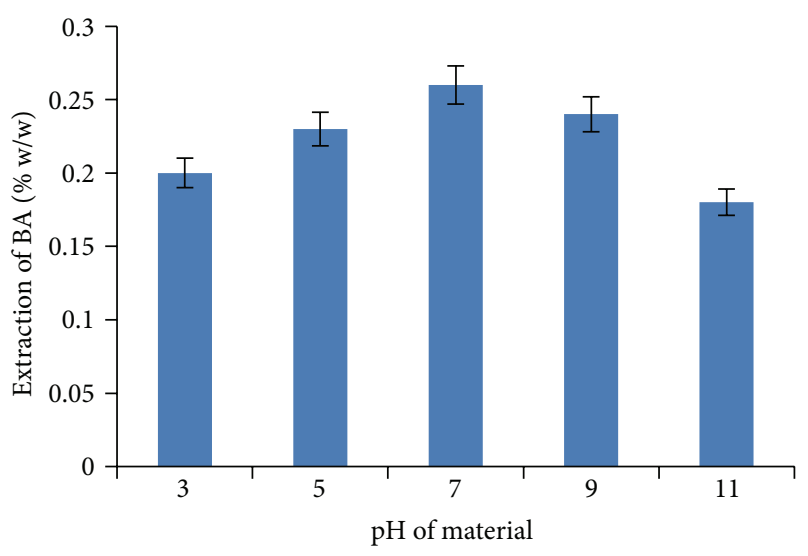

FIGURE 9: The effect of stirring extraction with methanol at varying $\mathrm{pH}$ values.

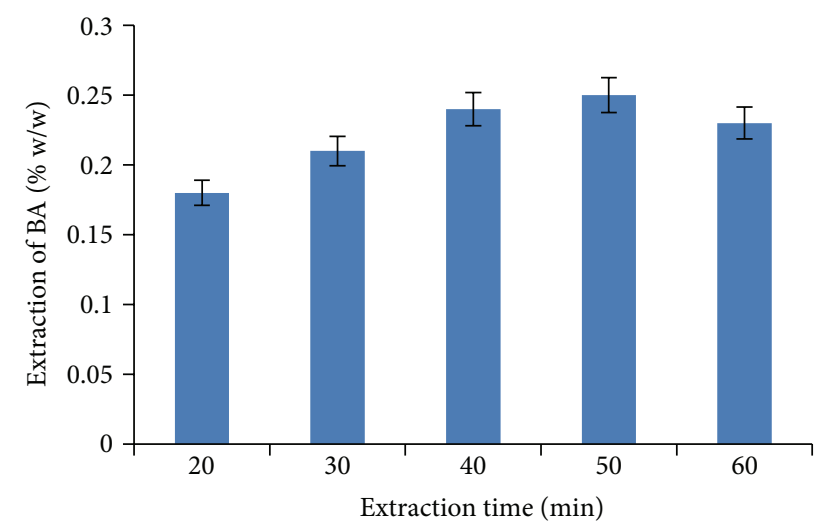

Figure 10: The effect of ultrasonic extraction time on percentage extraction of BA.

3.3. Optimization of $p H$ of Material (Plant Bark). In order to obtain the maximum recovery of BA from the bark of $Z$. jujubae with methanol as a solvent, extractions were carried out at differing $\mathrm{pH}(3,5,7,9$, and 11$)$ values. Results unveil that the maximum recovery of BA $(0.26 \% \mathrm{w} / \mathrm{w})$ was seen at $\mathrm{pH}$ 7. Similar reports have already been done by previous researchers on other plant secondary metabolites [16]. As shown in Figure 9, the extraction yield of BA increased as the $\mathrm{pH}$ values increased from 3 to 7 but decreased at $\mathrm{pH}$ values higher than 7 because the covalent bonding between plant material and the solvent becomes weak at $\mathrm{pH}$ higher than 7 . When $\mathrm{pH}$ value is increased from 3 to 7 , the extraction yield of $\mathrm{BA}$ increases due to the fact that stability of the extracted BA is maintained and is the highest at $\mathrm{pH} 7$, and at $\mathrm{pH}$ values above 7 , the reduction in the stability of the extracted compound, that is, BA, is observed.

3.4. Process Time Optimization. Optimization of the process time for the maximum recovery of BA from the plant material depended upon the type of extraction technique used. In stirring extraction technique, the efficiency of methanol used for maximum extraction was at $160 \mathrm{~min}$ yielding $0.27 \% \mathrm{w} / \mathrm{w}$

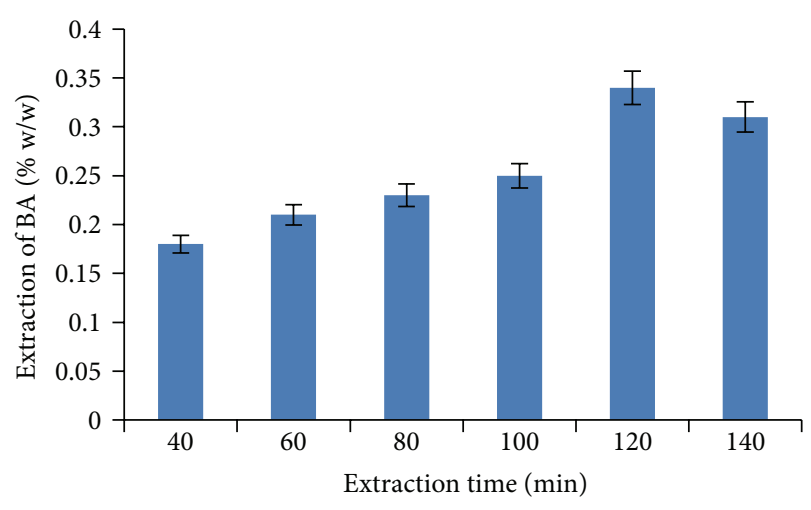

FIGURE 11: The effect of soxhlet extraction time on percentage extraction of BA.

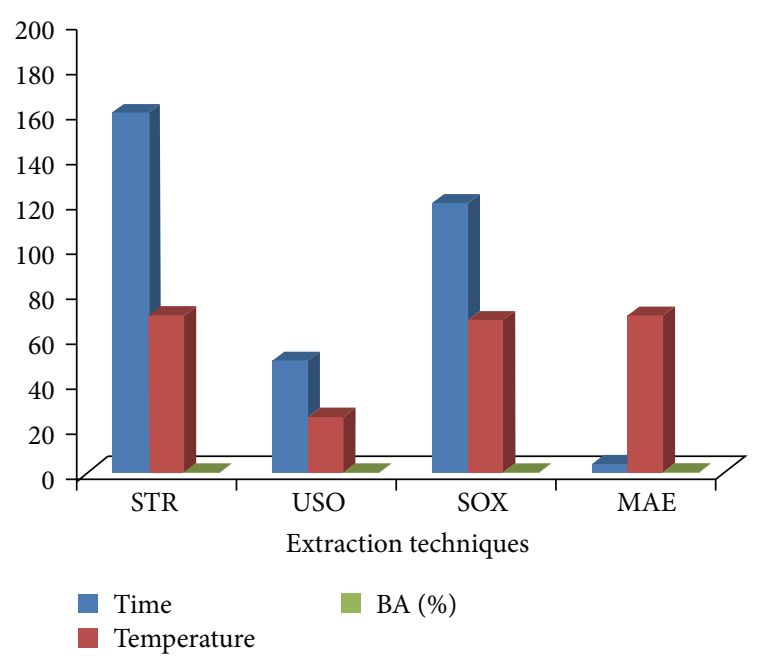

FIGURE 12: Comparison of percentage extraction of BA from bark of $Z$. jujubae by different extraction techniques.

of BA. Figure 10 shows that, for USO extraction, the maximum recovery of BA $(0.25 \% \mathrm{w} / \mathrm{w})$ was obtained when the bark material was extracted in sonicator for $50 \mathrm{~min}$.

For SOX extraction, the recovery of BA (Figure 11) was found to be maximum $(0.34 \% \mathrm{w} / \mathrm{w})$ when the material was extracted with methanol for $120 \mathrm{~min}$. As the process time was increased to $140 \mathrm{~min}$, the percentage extraction of BA decreased due to partial breakdown of the material.

To obtain maximum recovery of BA $(0.39 \% \mathrm{w} / \mathrm{w})$ using MAE, the exposure time of flask containing bark powder and methanol for microwave irradiation was found to be $4 \mathrm{~min}$. Additionally, the authors are also concerned about the cost effectiveness of the extraction process so MAE turned out to be the apt extraction technique for the extraction of BA, as it is the quickest requiring the least extraction time. The recovery of BA was significantly high when MAE was used as compared to SOX, STR, and USO extraction techniques.

3.5. Optimization of the Process Temperature. As the boiling point of methanol is $\sim 65^{\circ} \mathrm{C}$, the maximum recovery of BA was obtained within the range of $64-70^{\circ} \mathrm{C}$ for all types of extraction techniques excluding USO extraction in which 


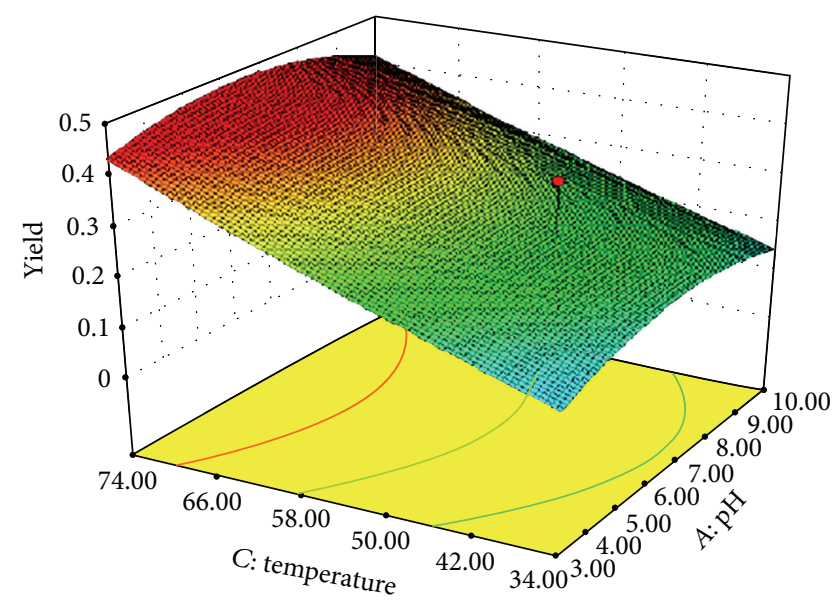

(a)

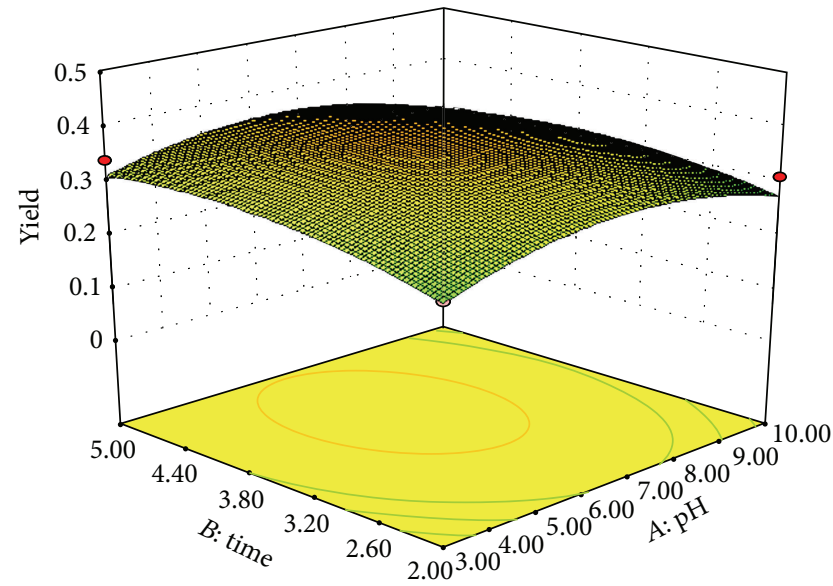

(b)

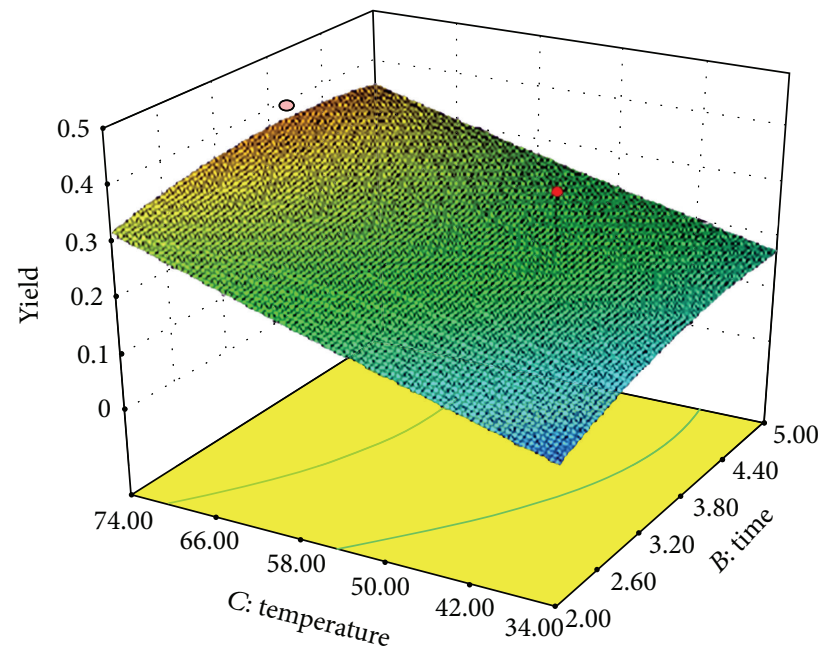

(c)

Figure 13: (a) Effect of $\mathrm{pH}$ and temperature on the yield of BA in the extraction process: 3D plot shows that \% BA yield (w/w) increases with increase in $\mathrm{pH}$ and extraction temperature. The third factor (process time) is fixed at $3.5 \mathrm{~min}$. (b) Effect of process time and pH on the BA yield in the extraction process: 3D plot showing increase in \% BA yield (w/w) with increase in $\mathrm{pH}$ and process time. The third factor (temperature) was fixed at $70.23^{\circ} \mathrm{C}$. (c) Effect of process time and temperature on the BA yield in the extraction process: 3D plot showing increase in \% BA yield $(\mathrm{w} / \mathrm{w})$ with increase in process time and extraction temperature. The third factor $(\mathrm{pH})$ is fixed at 6.5.

maximum recovery was obtained at room temperature. Figure 12 shows that process temperatures at which the percentage extraction of BA was maximum using various extraction techniques were found to be $70^{\circ} \mathrm{C}(0.27 \% \mathrm{w} / \mathrm{w})$, $25^{\circ} \mathrm{C}(0.25 \% \mathrm{w} / \mathrm{w}), 68^{\circ} \mathrm{C}(0.34 \% \mathrm{w} / \mathrm{w})$, and $70^{\circ} \mathrm{C}(0.39 \% \mathrm{w} / \mathrm{w})$ for STR, USO, SOX, and MAE techniques, respectively.

3.6. Selection of the Most Efficient Extraction Technique. Using the optimized parameters described above, four types of extraction techniques, namely, stirring extraction, ultrasonic extraction, soxhlet extraction, and microwave assisted extraction, were tried to attain the maximum recovery of betulinic acid from the dried and pulverized bark powder of Z. jujubae.

In stirring extraction technique, with methanol as a solvent at $70^{\circ} \mathrm{C}$ for $160 \mathrm{~min}, 0.27 \% \mathrm{w} / \mathrm{w}$ of BA was obtained.
For ultrasonic assisted extraction, the maximum percentage extraction of $\mathrm{BA}(0.25 \% \mathrm{w} / \mathrm{w})$ was recovered at $25^{\circ} \mathrm{C}$ with the process time of $50 \mathrm{~min}$. In order to obtain maximum recovery of BA $(0.34 \% \mathrm{w} / \mathrm{w})$ with soxhlet extraction, the bark material was extracted with methanol at $68^{\circ} \mathrm{C}$ for $120 \mathrm{~min}$. Figure 12 unveils that, by using MAE, the extraction \% of BA was found to be maximum $(0.39 \% \mathrm{w} / \mathrm{w})$ when the material was irradiated for $4 \mathrm{~min}$ at $70^{\circ} \mathrm{C}$.

Thus microwave assisted extraction turns out to be the most appropriate, the quickest, and the most proficient technique for the maximum recovery of betulinic acid from the bark of $Z$. jujubae.

3.7. Optimization of MAE Extraction Using RSM. As explained above (Section 3.6), MAE extraction technique turns out to be the most proficient technique, the three 
TABLE 2: Design matrix for the optimization of extraction parameters for maximum recovery of betulinic acid as response.

\begin{tabular}{|c|c|c|c|c|c|c|}
\hline \multirow{2}{*}{ Run } & \multirow{2}{*}{ Type } & \multicolumn{3}{|c|}{ Factors } & \multicolumn{2}{|c|}{ BA yield (\% w/w) } \\
\hline & & $\mathrm{pH}$ & Time (min) & Temp. $\left({ }^{\circ} \mathrm{C}\right)$ & Observed & Predicted \\
\hline 1 & Center & 6.50 & 3.50 & 45.00 & 0.21 & 0.24 \\
\hline 2 & Center & 6.50 & 3.50 & 45.00 & 0.21 & 0.24 \\
\hline 7 & Center & 6.50 & 3.50 & 45.00 & 0.21 & 0.24 \\
\hline 8 & Center & 6.50 & 3.50 & 45.00 & 0.21 & 0.24 \\
\hline 16 & Center & 6.50 & 3.50 & 45.00 & 0.35 & 0.37 \\
\hline 19 & Center & 6.50 & 3.50 & 45.00 & 0.21 & 0.24 \\
\hline 3 & Axial & 6.50 & 3.50 & 70.23 & 0.4 & 0.44 \\
\hline 6 & Axial & 0.61 & 3.50 & 45.00 & 0.06 & 0.07 \\
\hline 15 & Axial & 12.39 & 3.50 & 45.00 & 0.1 & 0.12 \\
\hline 17 & Axial & 6.50 & 3.50 & 19.77 & 0.08 & 0.09 \\
\hline 18 & Axial & 6.50 & 6.02 & 45.00 & 0.21 & 0.24 \\
\hline 20 & Axial & 6.50 & 0.98 & 45.00 & 0.07 & 0.09 \\
\hline 4 & Factorial & 10.00 & 5.00 & 60.00 & 0.25 & 0.26 \\
\hline 5 & Factorial & 3.00 & 5.00 & 30.00 & 0.06 & 0.09 \\
\hline 9 & Factorial & 10.00 & 5.00 & 30.00 & 0.12 & 0.14 \\
\hline 10 & Factorial & 3.00 & 2.00 & 60.00 & 0.24 & 0.26 \\
\hline 11 & Factorial & 10.00 & 2.00 & 60.00 & 0.29 & 0.31 \\
\hline 12 & Factorial & 3.00 & 5.00 & 60.00 & 0.33 & 0.34 \\
\hline 13 & Factorial & 3.00 & 2.00 & 30.00 & 0.04 & 0.06 \\
\hline 14 & Factorial & 10.00 & 2.00 & 30.00 & 0.05 & 0.04 \\
\hline
\end{tabular}

significant factors affecting $\mathrm{BA}$ recovery $(A: \mathrm{pH}, B$ : time, and $C$ : temperature) were optimized using RSM in MAE extraction method.

The predicted and observed responses in terms of \% recovery of BA (w/w) have been shown in Table 2 . The level of $\mathrm{BA}$ recovery was given by the second-order regression equation (1), attained after ANOVA in terms of actual factors (Table 3).

BA \%yield (w/w):

$$
\begin{aligned}
Y= & 0.261093+0.006157 A+0.30188 B \\
& +0.104609 C-0.0075 A B \\
& -0.0075 A C-0.0125 B C \\
& -0.05518 A^{2}-0.03043 B^{2} \\
& +0.004926 C^{2} \pm 0.047
\end{aligned}
$$

where $Y$ is the response symbolizing the yield \% of BA $(w / w)$ and $A, B$, and $C$ are coded values of $\mathrm{pH}$, process time, and temperature.

The coefficient of regression $\left(R^{2}\right)$ was found to be 0.9059 for BA recovery. This specifies confidence of $>95 \%$ in the results signifying precise dependence between experimental and predicted values. The experimental value of $R^{2}>0.9059$ indicates rightness of the model. To define the experimental factors producing signals that are large in assessment to the noise, statistical analysis is needed. The appropriate precision measures signal-to-noise ratio and a value $>4$ is desirable, so the adequate precision value of 12.993 for BA recovery specified the usage of model for directing the design space.
Analysis of variance for the betulinic acid extracted from $Z$. jujubae roots obtained from this design was given in Table 3.

The model $F$-value and $P$ value of 10.7 and 0.0005 for $\mathrm{BA}$ recovery unveiled that the model is significant (Table 3 ). Values of "Prob. $>F$ " less than 0.0500 show model terms which are significant. The "lack of fit $F$-value" of 0.62 implied the lack of fit is not significant relative to the pure error. $3 \mathrm{D}$ graphs define the relations of the variables and also the optimum level of each variable for maximum BA recovery (Figures 13(a), 13(b), and 13(c)). The model prediction for maximum BA recovery $(0.44 \% \mathrm{w} / \mathrm{w})$ was at temperature $70.23^{\circ} \mathrm{C}, \mathrm{pH} 6.5$, and process time of $3.5 \mathrm{~min}$.

3.8. Evaluation of the Model. At the optimum levels of pH: 6.5 , time: $3.5 \mathrm{~min}$, and temp.: $70.23^{\circ} \mathrm{C}$, as predicted by RSM, the experimental response for BA recovery was $0.4 \%$ (w/w) quantified by HPLC which is $\pm 0.04 \%$ to the predicted response of $0.44 \%(\mathrm{w} / \mathrm{w})$. Hence the statistical model was successfully evaluated. It was observed that process time and temperature conditions for extraction processes play a major role in maximum recovery of BA from Ziziphus jujubae which is related to the extraction of triterpenoid, oleanolic acid, from Lantana camara [17]. Recovery of BA increased when $\mathrm{pH}$ was increased from 3 to 6 and was maximum at $\mathrm{pH} 6.5$ but further increase in $\mathrm{pH}$ decreased the BA yield due to the fact that the covalent bonding between plant material and the solvent becomes weak at $\mathrm{pH}$ higher than 7. Similarly with increase in process time and temperature conditions, the \% BA yield (w/w) also increased as shown in Figure 13. Therefore it was seen that the highest recovery of BA $(0.4 \% \mathrm{w} / \mathrm{w})$ from Ziziphus jujubae was obtained using 
TABLE 3: ANOVA for response surface quadratic model to verify whether developed model is significant or nonsignificant.

\begin{tabular}{lccccc}
\hline Source & Sum of squares & Degree of freedom & Mean square & F-value & $\begin{array}{c}\text { P value } \\
\text { Prob. }>F\end{array}$ \\
\hline Model & 0.21985 & 9 & 0.024 & 10.6998 & 0.0005 \\
$A$-pH & 0.00052 & 1 & 0.0005 & 0.22679 & 0.6441 \\
$B$-time & 0.01245 & 1 & 0.012 & 5.45133 & 0.0417 \\
$C$-temp. & 0.14945 & 1 & 0.149 & 65.4605 & $<0.0001$ \\
$A B$ & 0.00045 & 1 & 0.0004 & 0.19711 & 0.6665 \\
$A C$ & 0.0045 & 1 & 0.0004 & 0.19711 & 0.6665 \\
$B C$ & 0.00125 & 1 & 0.0012 & 0.54752 & 0.4763 \\
$A^{2}$ & 0.04388 & 1 & 0.044 & 19.2191 & 0.0014 \\
$B^{2}$ & 0.01334 & 1 & 0.013 & 5.84505 & 0.0362 \\
$C^{2}$ & 0.00035 & 1 & 0.0003 & 0.15316 & 0.7037 \\
Residual & 0.02283 & 10 & 0.0022 & & 0.6930 \\
Lack of fit & 0.00875 & 5 & 0.0017 & 0.62107 & Nonsignificant \\
\hline
\end{tabular}

MAE technique at $\mathrm{pH} 6.5$, process time of $3.5 \mathrm{~min}$, and at $70.23^{\circ} \mathrm{C}$ temperature.

\section{Conclusion}

By assessing various extraction methods for extraction of betulinic acid, MAE was the most resourceful. For product recovery with solvents of ethanol, methanol, hexane, acetone, and ethyl acetate, methanol obtained maximum recovery percentage of $\mathrm{BA}(0.39 \% \mathrm{w} / \mathrm{w})$, using MAE, at $\mathrm{pH} 7$ when 1:50 bark powder : methanol ratio was used. The extraction temperatures and the time required for the highest extraction percentage of BA for different techniques, namely, stirring extraction, ultrasonic extraction, soxhlet extraction, and $\mathrm{MAE}$, were found to be $70^{\circ} \mathrm{C}, 160 \mathrm{~min} ; 25^{\circ} \mathrm{C}, 50 \mathrm{~min} ; 68^{\circ} \mathrm{C}$, $120 \mathrm{~min}$; and $70^{\circ} \mathrm{C}, 4 \mathrm{~min}$, respectively, yielding $0.27 \%, 0.25 \%$, $0.34 \%$, and $0.39 \% \mathrm{w} / \mathrm{w}$ of BA correspondingly. When RSM was employed in MAE, it predicted the maximum recovery of BA $(0.44 \% \mathrm{w} / \mathrm{w})$ which is $\pm 0.04 \%$ to the experimental $\mathrm{BA}$ yield $(0.4 \% \mathrm{w} / \mathrm{w})$ at the optimum parameters of $\mathrm{pH}: 6.5$; process time: $3.5 \mathrm{~min}$; and temperature: $70.23^{\circ} \mathrm{C}$. Therefore, MAE was found to be the most efficient extraction technique for rapid and maximum percentage extraction of betulinic acid from the dried bark material of Ziziphus jujubae.

\section{Acknowledgment}

The authors sincerely acknowledge support and necessary facilities by UIET, MDU, Rohtak where the research work was carried out.

\section{References}

[1] C. C. C. R. de Carvalho and M. M. R. da Fonseca, "Biotransformation of terpenes," Biotechnology Advances, vol. 24, no. 2, pp. 134-142, 2006.

[2] V. Zuco, R. Supino, S. C. Righetti et al., "Selective cytotoxicity of betulinic acid on tumor cell lines, but not on normal cells," Cancer Letters, vol. 175, no. 1, pp. 17-25, 2002.
[3] Z. Yueqin, M. C. Recio, S. Máñez, R. M. Giner, M. CerdáNicolás, and J. L. Rios, "Isolation of two triterpenoids and a biflavanone with anti-inflammatory activity from Schinus molle fruits," Planta Medica, vol. 69, no. 10, pp. 893-898, 2003.

[4] M. L. Schmidt, K. L. Kuzmanoff, L. Ling-Indeck, and J. M. Pezzuto, "Betulinic acid induces apoptosis in human neuroblastoma cell lines," European Journal of Cancer, vol. 33, no. 12, pp. 2007-2010, 1997.

[5] B. R. Copp, "Antimycobacterial natural products," Natural Product Reports, vol. 20, no. 6, pp. 535-557, 2003.

[6] W. Schühly, J. Heilmann, I. Çalis, and O. Sticher, "New triterpenoids with antibacterial activity from Zizyphus joazeiro," Planta Medica, vol. 65, no. 8, pp. 740-743, 1999.

[7] X. Pan, G. Niu, and H. Liu, "Comparison of microwaveassisted extraction and conventional extraction techniques for the extraction of tanshinones from Salvia miltiorrhiza bunge," Biochemical Engineering Journal, vol. 12, no. 1, pp. 71-77, 2002.

[8] J. Hao, W. Han, S. Huang, B. Xue, and X. Deng, "Microwaveassisted extraction of artemisinin from Artemisia annua L.," Separation and Purification Technology, vol. 28, no. 3, pp. 191196, 2002.

[9] M. Letellier, H. Budzinski, L. Charrier, S. Capes, and A. M. Dorthe, "Optimization by factorial design of focused microwave assisted extraction of polycyclic aromatic hydrocarbons from marine sediment," Fresenius' Journal of Analytical Chemistry, vol. 364, no. 3, pp. 228-237, 1999.

[10] J. L. Luque-García and M. D. L. de Castro, "Ultrasound: a powerful tool for leaching," Trends in Analytical Chemistry, vol. 22, no. 1, pp. 41-47, 2003.

[11] L. Hui, O. Etsuzo, and I. Masao, "Effects of ultrasound on extraction of saponin from ginseng," Japanese Journal of Applied Physics 1, vol. 33, no. 5, pp. 3085-3087, 1994.

[12] M. Vinatoru, M. Toma, O. Radu, P. I. Filip, D. Lazurca, and T. J. Mason, "The use of ultrasound for the extraction of bioactive principles from plant materials," Ultrasonics Sonochemistry, vol. 4, no. 2, pp. 135-139, 1997.

[13] V. Mandal, Y. Mohan, and S. Hemalatha, "Microwave assisted extraction-an innovative and promising extraction tool for medicinal plant research," Pharmacognosy Review, vol. 1, no. 1, pp. 7-18, 2007. 
[14] G. E. P. Box and K. G. Wilson, "On the experimental attainment of optimum conditions," Journal of the Royal Statistical Society, vol. 13, no. 1, pp. 1-45, 1951.

[15] S. Wright, S. Jeffrey, and R. Mantoura, "Evaluation of methods and solvents for pigment extraction," in Phytoplankton Pigments in Oceanography: Guidelines to Modern Methods', S. W. Jeffrey, R. F. C. Mantoura, and S. W. Wright, Eds., pp. 261-282, 1997.

[16] Z. Q. Zhang, X. Q. Pang, Z. L. Ji, and Y. M. Jiang, "Role of anthocyanin degradation in litchi pericarp browning," Food Chemistry, vol. 75, no. 2, pp. 217-221, 2001.

[17] R. M. Banik and D. K. Pandey, "Optimizing conditions for oleanolic acid extraction from Lantana camara roots using response surface methodology," Industrial Crops and Products, vol. 27, no. 3, pp. 241-248, 2008. 

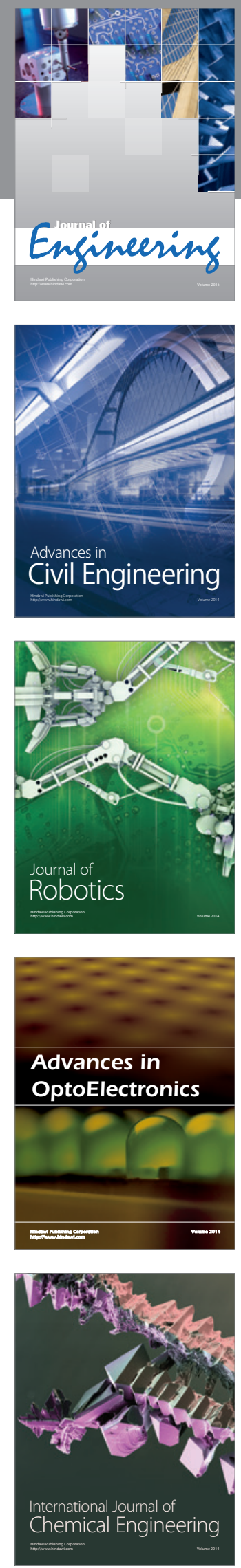

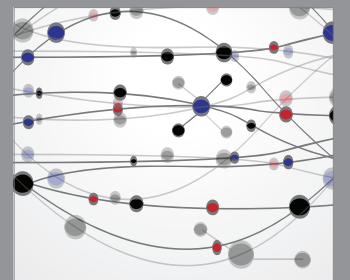

The Scientific World Journal
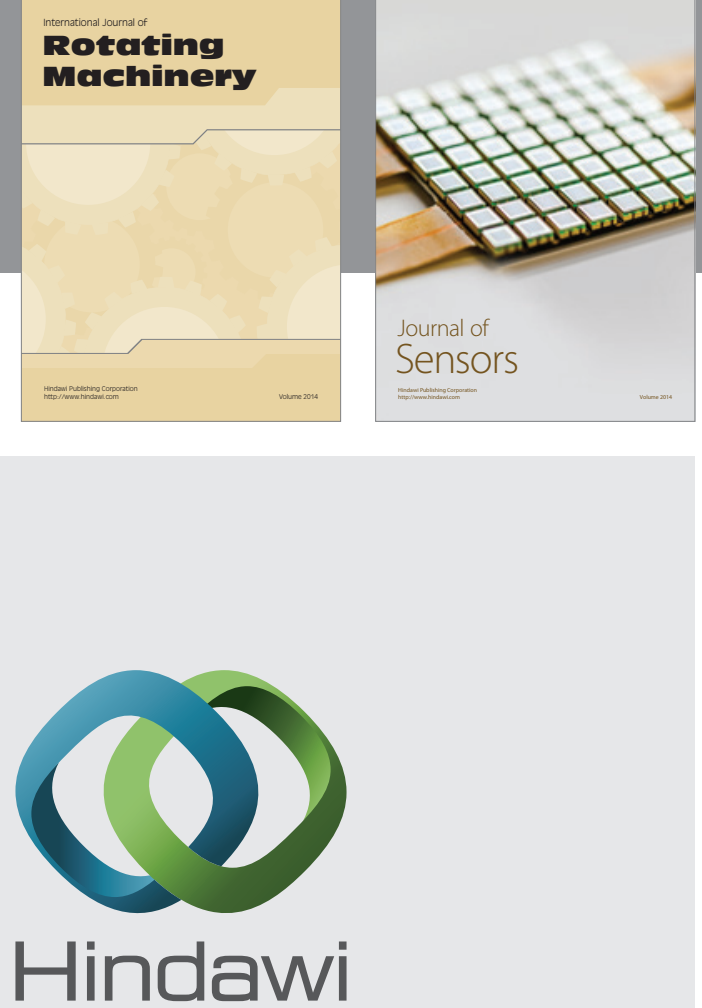

Submit your manuscripts at http://www.hindawi.com
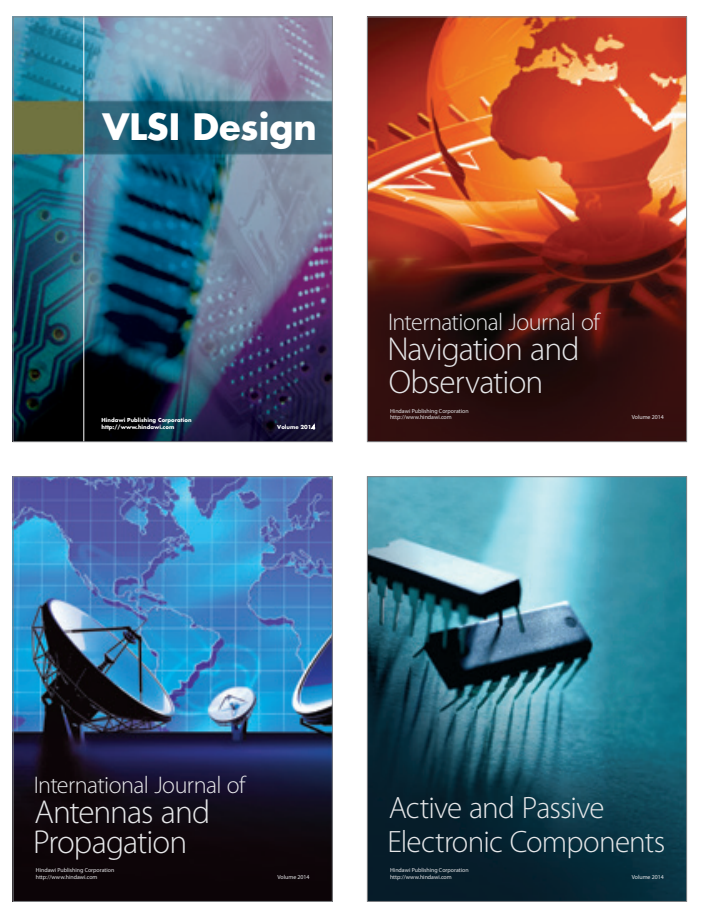
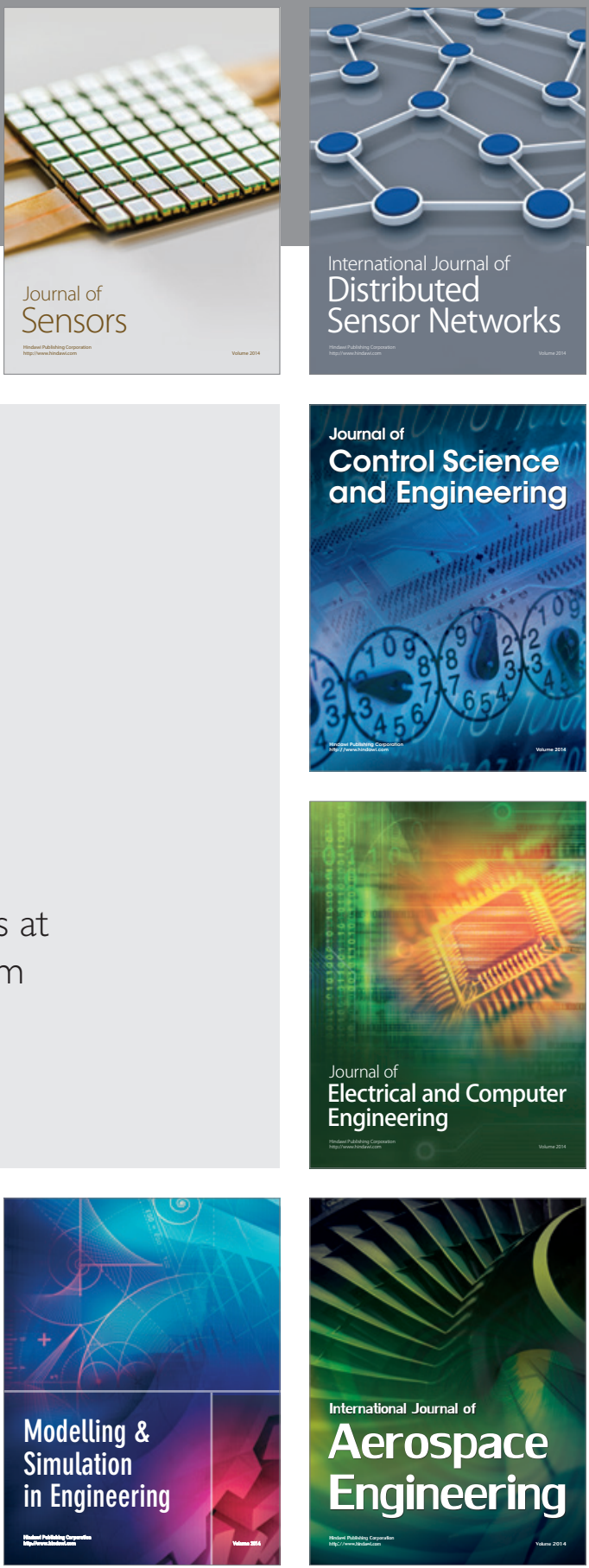

Journal of

Control Science

and Engineering
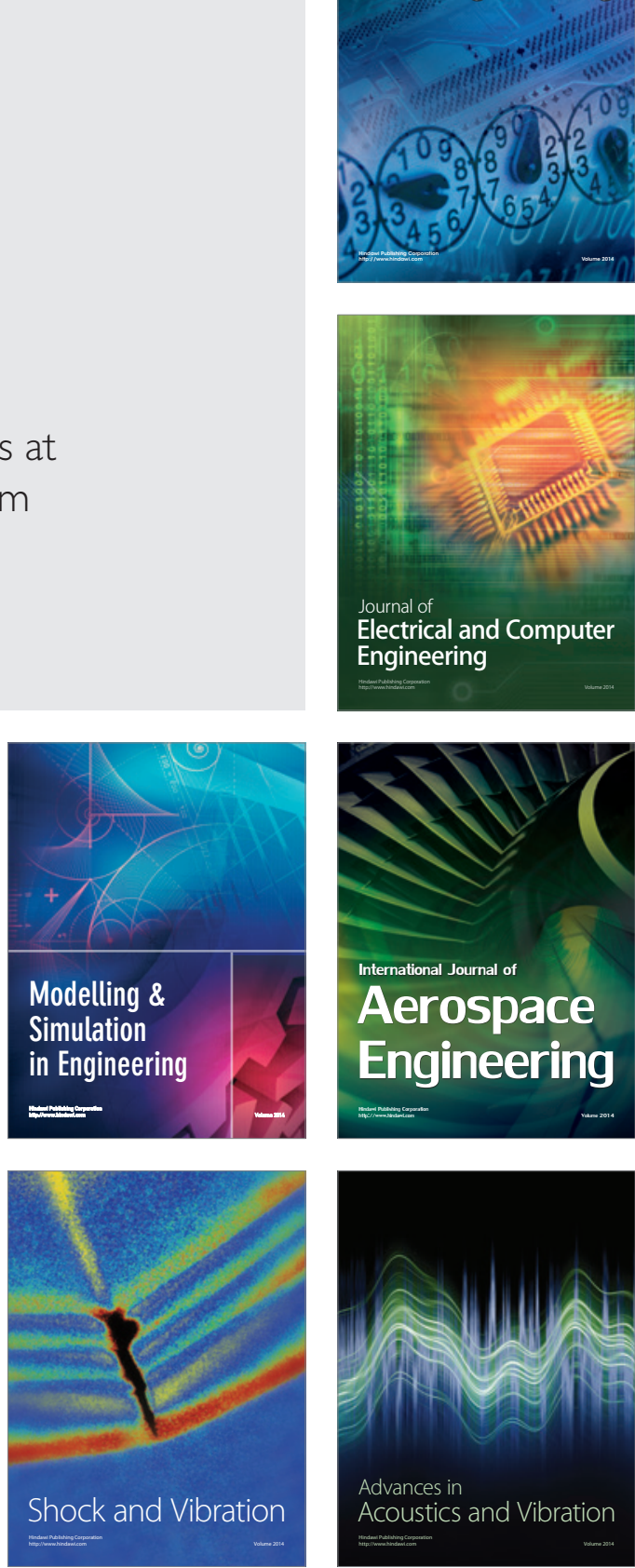